\title{
Impacto del entrenamiento deportivo adaptado en salud de pacientes con lesiones medulares
}

\author{
Impact of adapted sports training in health of patients with spinal cord injuries
}

\section{Sr. Editor:}

Las personas con lesión medular (LM), que practican el deporte, tienen menor riesgo de enfermar (1). El deporte permite mejorar la calidad de vida y la participación social (2). El Dr. Guttman (1948), descubrió los beneficios de esta actividad en pacientes con LM durante la rehabilitación (3) y ahora se denomina Terapia Deportiva Adaptada (TDA).

La LM, considerada como discapacidad de alta complejidad, afecta las funciones sensitivas, motoras, esfinterianas (vesicales e intestinales), sexuales y psicológicas, provocando limitación funcional y restricción social. Es frecuente la LM de nivel parapléjico y de tipo completa, en varones, en edades de 30 y 50 años, en solteros (4). Múltiples complicaciones acompañan a la LM, entre ellas, las infecciones respiratorias, la espasticidad, el dolor neuropático, las infecciones urinarias, las constipaciones, disfunción eréctil e infertilidad, y depresión (3).

En Perú, el Instituto Nacional de Rehabilitación (INR) dando cumplimiento a la Ley $\mathrm{N}^{\circ} 29973$, crea la Terapia Deporte Adaptado en los departamentos de Funciones Mentales y Motoras. El equipo de rehabilitación integral de lesiones medulares del INR, tiene el servicio de TDA, y brinda el entrenamiento deportivo para mejorar funcionalidad durante el tiempo de hospitalización, con la finalidad de preparar al paciente a participar en el deporte con fines de mejorar su salud, de competir a futuro nivel nacional e internacional como las paralimpiadas, incluyendo a todo tipo de paciente con LM (5).
El ingreso del paciente al servicio TDA es por prescripción médica, los fisioterapeutas evalúan la función cardiorrespiratoria y el gesto motor, para determinar las condiciones físicas; luego se plantea el programa de terapia cardiorrespiratorio (TCR), terapia deportiva individual (TDI) y grupal (TDG), para adquirir habilidades del deporte en silla de ruedas (SR) o en parado según LM (6).

La TCR dura 60 minutos, tiene como objetivo aumentar la capacidad vital y resistencia. La TDI dura 45 minutos y sirve para alinear, orientar los ejes anatómicos, estabilizar los segmentos proximales del tronco a través de técnicas kinésicas de terapia manual. La TDG dura 90 minutos, consiste en la práctica en campo del manejo de la silla de ruedas en el básquet y tenis de mesa para los pacientes parapléjicos y de bochas para los pacientes cuadripléjicos; y para los pacientes que caminan se practica el tenis de mesa en parado (7).

Los efectos positivos se dan a nivel de deficiencias, limitaciones y restricciones, como recomienda la Clasificación Internacional del Funcionamiento y Discapacidad CIF- OMS (8). En la LM con espasticidad y rigidez, se obtienen flexibilidad de los músculos hipertónicos debido a la fuerza externa que ejercen los brazos y el tronco al manejar la silla de ruedas sobre las extremidades inferiores, también al mover el tronco sobre una base bipodal, generan relajación de los músculos espásticos (9). En aquellos con dolor neuropático, el entrenamiento disminuye el dolor, porque el cerebro se distrae en una actividad donde el esfuerzo físico por más de 30 minutos genera endorfinas (2). A nivel visceral el deporte tiene

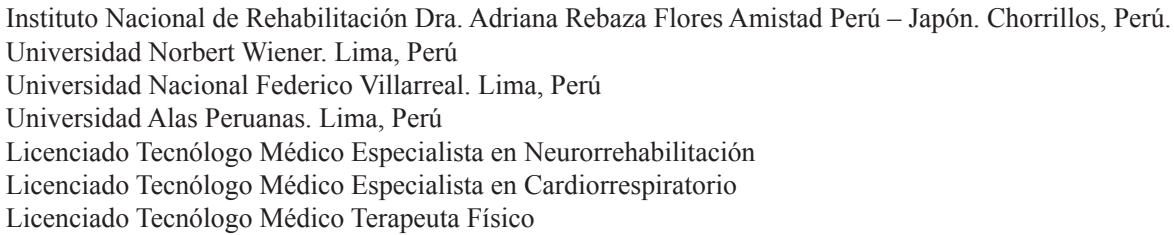


efectos mecánicos sobre la vejiga e intestino porque al moverse el paciente en silla de ruedas o parado genera vibraciones sobre los mecanorreceptores de Paccini de la vejiga y del intestino grueso, facilitando las evacuaciones de la micción y defecación (10),

A nivel funcional refuerza las actividades de la vida diaria y permite la participación social. Luego del alta, siguen practicando TDA, ahora algunos son deportistas que están compitiendo a nivel nacional y han sido seleccionados para los deportes Paralímpicos (7).

Porúltimo, la TDAactiva el sistema neuroendocrino e inmunológico, mejorando el estado emocional, disminuyendo el estrés, apertura la motivación y logros personales que le permiten afrontar la discapacidad sin barreras, mejorando notablemente la calidad de vida. Entonces podríamos sugerir que la TDA en la LM provoca efectos positivos en la salud.

\section{Julio Granados Carrera ${ }^{1,2,3,4, a}$, Jimmy Vásquez Mego $^{1, \mathrm{~b}}$ Javier Espinoza Castillo ${ }^{1, \mathrm{c}}$}

\section{REFERENCIAS BIBLIOGRÁFICAS}

1. Fidler A, Schmidt M, Vauhnik J. Ways that people with a chronic spinal cord injury participate in sport in the Republic of Slovenia. Journal of Physical Education \& Sport. 2017; 17(3):1892-1898.

2. Côté-Leclerc F, Duchesne G, Bolduc P, et al. How does playing adapted sports affect quality of life of people with mobility limitations? Results from a mixed-method sequential explanatory study. Health Qual Life Outcomes. 2017; 15: 22. doi: 10.1186/ s12955-017-0597-9
3. Guttmann L. Lesiones medulares tratamiento global e investigación. Barcelona, España: Editorial JIMS; 1981.

4. Kivisild A, Sabre L, Tomberg T, et al. Health-related quality of life in patients with traumatic spinal cord injury in Estonia. Spinal Cord. 2014; 52(7):570-575.

5. O'Neill S, Maguire S. Patient perception of the impact of sporting activity on rehabilitation in a spinal cord injuries unit. Spinal Cord. 2004; 42(11): 627-630. DOI: 10.1038/sj.sc.3101651

6. Moya R. Serie 5 Infórmate sobre.... Deporte Adaptado. Madrid, España: Editorial Cepeat Imserso; 2014.

7. Tweedy S M, Vanlandewijck Y C. International Paralympic Committee position stand-background and scientific principles of classifi cation in Paralympic sport. Br J Sports Med. 2011; 45:259269.

8. World Health Organization. International Classification of Functioning, Disability and Health: ICF short version. Geneva: World Health Organization; 2001.

9. Nightingale T, Rouse P, Thompson D, Bilzon J. Measurement of physical activity and energy expenditure in wheelchair users: Methods, considerations and future directions. Sports Medicine. 2015; 3:10.

10. Morriën F, Taylor M, Hettinga, F. Biomechanics in Paralympics: Implications for Performance. International. Int J Sports Physiol Perform. 2017; 12(5):578-589. doi: 10.1123/ijspp.2016-0199

Recibido: 29/05/2018 